\title{
LIBRARY
}

ARCTIC RESEARCH LABORATORY

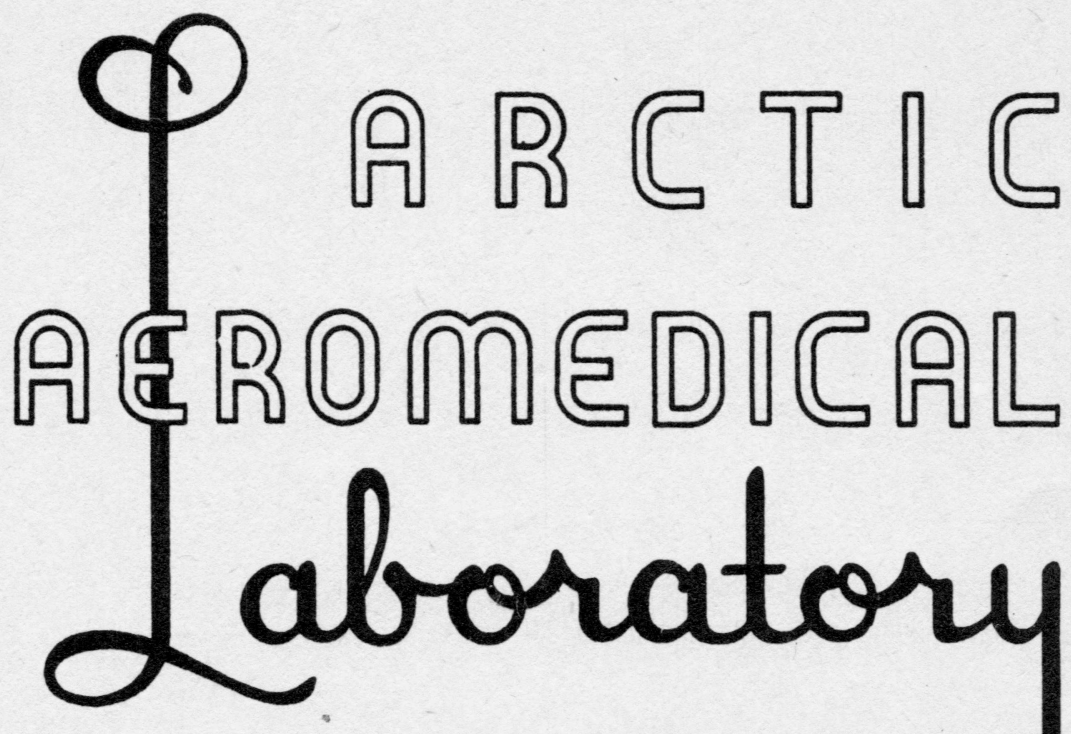

ANGIOSTOMY CANNULAE FOR THE STUDY OF PULMONARY CIRCULATION

PROJECT NUMBER 22-1301-0002 RESEARCH REPORT

LADD AIR FORCE BASE $\begin{array}{llllll}A & L & A & S & K & A\end{array}$ 


\title{
ANGIOSTOMY CANNULAE FOR THE STUDY OF PULMONARY CIRCULATION
}

\author{
GEORGE W. MATHER \\ G.G. NAHAS \\ ALLAN HEMINGWAY \\ University of Minnesota \\ School of Veterinary Medicine
}

Contract Number $18(600)-413$

PROJECT NUMBER 22-1301-0002

RESEARCH REPORT

Alaskan Air Command

ARCTIC AERO MEDICAL LABORATORY

LADD AIR FORCE BASE

March 1953 


\section{ANGIOSTOMY CANNULAE FOR THE STUDY OF PULMONARY CIRCULATION}

Iondon (1) used anglostomy cannulae for the purpose of directing hypodermic needles into the larger thoracic ressels. Daly (2) reported the measurement of pulmonary arterial pressure in the unanesthetized dog by means of the London Type canmulae. Johnson, Hamilton, Katz, and Weinstein (3) in the same year studied the dynamics of pulmonary clrculation by means of hypodermic mometers, the needles being placed In the aorta, pulmonary artery, and pulmonary vein. Hamilton, Woodbury, and Vogt (4) studied differential pressures in the lesser circulation of the unanesthetized dogs using anglostomy cannulae and hypodermic manometers. Katz and Steinitz (5) developed a modification of the angiostomy cannulae used by Hamilton, and used their cannulae in measuring pulmonary arterial pressures.

The purpose of this paper is to report the development of a technique permitting direct access to the atria and large thoracic vessels of unanesthetized dogs under conditions which may be compared to normal.

\section{MITHODS:}

Two rarieties of cannulae were developed and used. The first variety, shown in figure la, consists of silver tubes ( $3 \mathrm{~mm}$. outside diameter)

This work was supported in part by contract \#AF18(600)-413 with the Alaskan Air Command Arctic Aeromedical Laboratory, Iadd AFB, Alaska.

Paper No. 2813, Scientific Journal Series, Minnesota Agricultural uxperiment Stat1on. 


\section{P ROJ ECT NUMBER 21-130 1-0002}

fitted with perforated silver plates, one type of which is trough-shaped, to fit over the left pulmonary artery. A second type is flat and oval in shape, suitable for attachment to the left atrium. The length of each silver tube is such that its distal end, the heart serving as reference point, will lie immediately under the skin of the chest wall. The perforated silver plates are made from $2 \mathrm{~mm}$. silver tock. The plate attachment that is fitted over the left palmonary artery is $8 \mathrm{~mm}$. Iong and of sufficient width so that when bent in a semicircle of the correct radius it extends over half the circumference of the vessel. The oval plate for attachment to the left auricle measurs $15 \mathrm{~mm}$. by $10 \mathrm{~mm}$. The cannula tube is fixed in an opening $5 \mathrm{~mm}$. from one end of the oval plato.

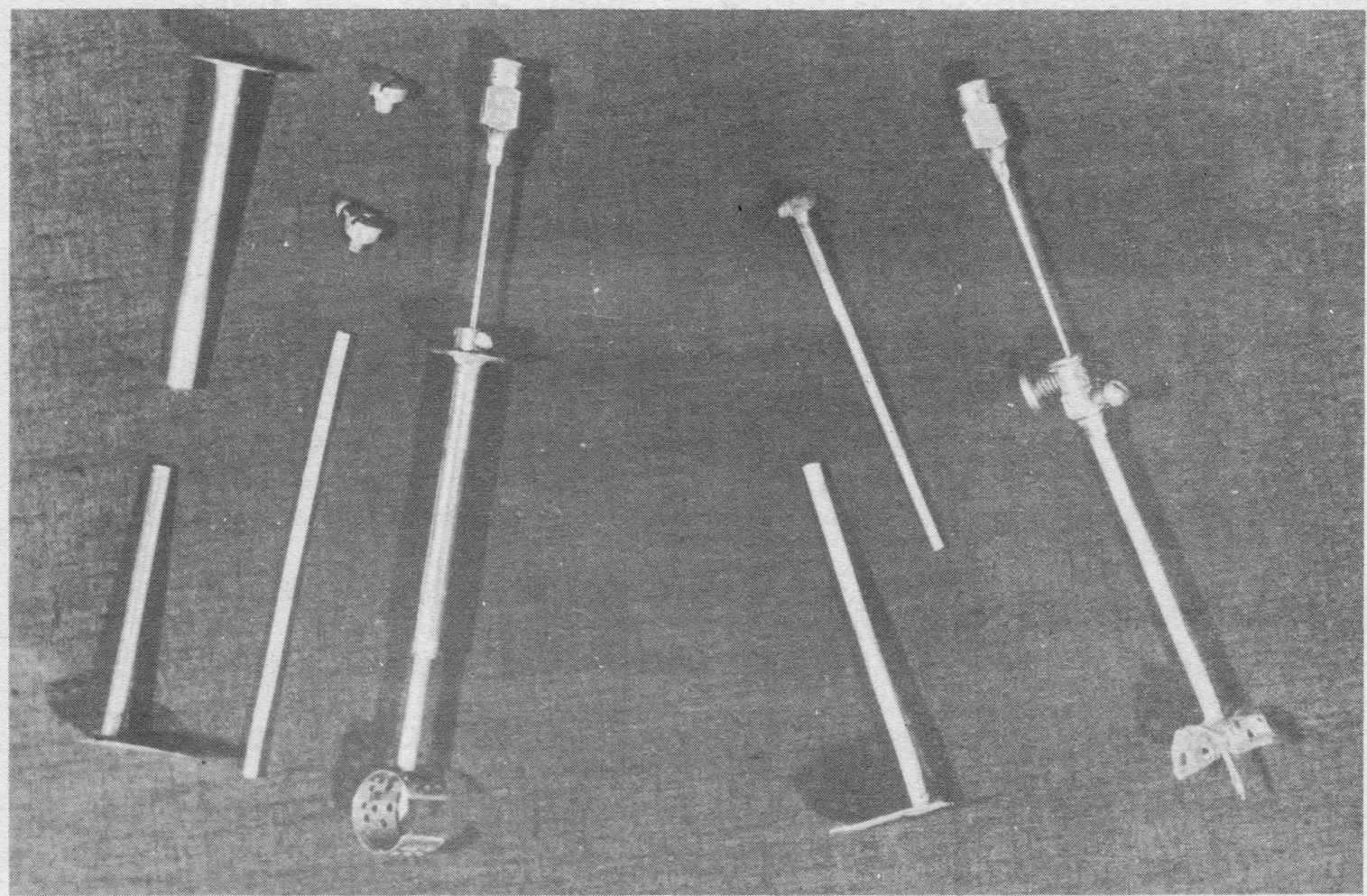

Figure 1. a, Silver cannulae (left side). b. Steel cannulae (right side) for surgical placement on left pulmonary artery and left atrium of dogs. 
Th1 arrangement allows placoment of the cannulae on the auricle 1mmediatelJ beneath the ontrance of the palmonary reins into the atriun. Stainless steel stilettes mat be used in the silver cannulee to prevent oceluding I1brin formations and bonding of the cannulae. These st1lettes are ado from 4 m. steinless steel rod; they aro fitted on one ond with t9 ellverplated brass mats. Hypodernic needies are fixed within the canmala by means of "coupling" bushings equipped with 2 set-screw. The se f1ttings: are 7 m. long and of sufficlent diameter os to 1 it closely over the distal end of the cannula. One set-screw serves to fix the bushing to the cannula; the second set-serew serves rigldly to secure a hpodermic needle whin the tube at the desired depth.

A second type of cannula, shown in figure $1 \mathrm{~b}$, is made of stainlese steol tubing. Fach cannula consists of 4 different parts: Two trabes, a proximal tube telescoping into distal one; and 2 end pieces, one "closing" end plece and one "cannulating" end piece. The preximal tube messures $6.5 \mathrm{~cm}$. long and $3 \mathrm{~mm}$. In external dieneter with a lumen of $1.5 \mathrm{~mm}$. The proximal tubes are fitted with perforated plates $0.2 \mathrm{~mm}$. thick and are bent to conform in shape with the organ orer which they are to be placed. One type is so shaped as to accommodate the left pulmonary artery and consists of a ring $10 \mathrm{~mm}$. In diameter and $4 \mathrm{~mm}$. Wde. The with of the alit in the open ring 18 adjustable in order to allow it to slip around the artery when the ressel is collapsed. This open ring is fitted with 10 an. Iength of polyethylene tubing of sufficient diameter to allow lipping the latter orer the band portion of the ring so as to close the open portion when the derice is placed around the left pulmonary artery. The tubing protects the ressel from possible traums from the free odges of the slit in the steel ring. The second type of perforated plate, designed to attach to the left atrial wall, is oval, flat and flexiblo. 
The distal tube of the cenurala, which telescope over the proximal tube, Is formed by a stainless teel tube $6 \mathrm{~cm}$. $10 \mathrm{ng}$ and $4 \mathrm{~mm}$. In external diameter. It dfstal and presents a clrcular perforated flange for attachnent to the chest vall. This arrangement onablos instantaneous adjustment of the length of the cannula to the variations in depth of the pulmonary artery or left atrium from the skin vurface. The inner apect of the llange ond of the distal cannula is throaded to the depth of 4 mit. so that olther of two ond pieces, a "elosing" or a "cannulat1ng" end piece, may be sereved into 1t.

The "closing" end plece 1. a large headed screw whlch thread into the Ilange and allows complete closure of the cannula when not in use.

The "canmilating" and plece is a bushing threaded to fit into the flange of the distal canmala. It is perforated in 1 ts conter so that hypodermie needles up to 14 gauge in size may be inserted, and is fitted vith a small set-serew which enables the fixing of the needle within the cannula.

It 1 s necessary to use lengths of suitably-sized polyethylene tubing as stiletter for these cannulae, to prevent fibrin occlusion.

The canmulae are placed about the left palmonary artery and attached to the left auricle through a thoractomy incision made in the left 4 th Intercostal pece. Hembutal anesthesia is used, and respiration is maintained by an electric nechanical respirator. The pericardial sac over the left pulmonary artery is incised, thereby exposing this vessel and the adjacent left auricle. The visceral layer of the pericerdium over the left pulmonary artery is Incised and freed from the vessel for a sufficient distance to allow the placoment of the canmala over or around the vessel, depending upon the type of canmula used. After placement, the $\nabla$ ifceral pericardiam is eutured, over the cannula end piece. The oval atrial cannula plate is 
sutured to the muscular wall of the left auricle. Care must be exercised to arold entering the chamber of the organ.

Aqueous penicilin (10,000 units) Is injected Into the pericardial and pleural sacs, after which they are closed with 400 silk guture. It is important that the atrial canmula be directed cranially and dorsally from Its attachment and that the pulmonary artery canmula be directed laterally. In event the steel telescoping cennulae are used, it is necessary at this time to place the distal portions of these cannulae over the proximal portions. Following the placement of the aborementioned stilettes within the tubes, the distal onds of the cannulae, either steel or alirer, are then fired to the chest wall in the subcutaneous fascla. The thoracotomy Incision is closed in three layers; the residual air in the pleural carities is then remored by asplration. The isin and subcutaneou fascia are sutured over the ends of the cannules. Procaine penic1111n (150,000 units) 1s administered intramuscularly.

Dogs aro raady for use one wok following surgical preparation. Prior to experimental study, the akin over the canmulae is anesthotized with $2 \%$ procaine hydrochloride solution. Incieions through the skin and superficial subcutaneous t1s tsues are to to exposa the distal ends of the cannulae. In the event steel cannulae have been used, the closing ond pieces and poljethylene tubing are renoved, and the "cannulating" and pleces are serewed into place. If s1lver canmulae have been used, the selel stIlettes are romored and the "coupling" burhings f1tted and fastened on tho onds of the s1lver tubes. The exact distances from the distal onds of the canmelae to the left atrial carity and to the pulmonary artery lumen may be determined by lowly inserting through the canmula 20 gage, $8 \mathrm{~cm}$. 10 s needles fitted with saline-i1lled syringes to which negative presure has 
been appl1ed. The depth at wich blood first appears in the syringe, indicates the desired position of the tip of the needle in the artery or atrium; this depth is marked on the needle with a small piece of zine oxide tape. Thi same neodle or another needle may then be used in the pulmonary artery or the left atrium for whatever purpose the investigator may desire. Presøures may be measured, semples may be taken, or temperature measuring devices may be placed within these vascular structures.

After completion of an experimental study, the needles are removed and the st1lettes are replaced. In the event steel cannulae have been used, the "closing" end pleces are replaced. The wounds are liberally powdered with sulfonamide, dressed with gause, and covered with plaster of Paris bandage. The bandage must corer the thorax of the animal and the base of the neck in order to adequately protect the wounds and limit infection. A second experimental study can be carried out 24 to 48 hours after the first. By following this procedure, it has been possible to use some animals as many as seven times within a period of 14 days.

\section{REFTERENCES}

1. Ipndon, I. S. Anglostomie und Organst of frochsel. All-Union-Institut fur Inxperimentelle Modizin, Moscow, 1935.

2. Daly, I. O. J. Phys. 1937, 21 15 P.

3. Johnson, V., Hamilton, W. T., Katz, I. H. and Weinstein, W. A. J. Phys. 1937, 120624.

4. Hamilton, W. R., Woodbury, R. A., Vogt, I. A. J. Phys. 1939, 12530.

5. Katz, I. H. and Steinitz, Y. A. J. Phys. 1941, 128433. 


\section{Distributed by USAF School of Aviation Medicine \\ Distribution Number 1892 \\ March 1953}

